\title{
Revista
}

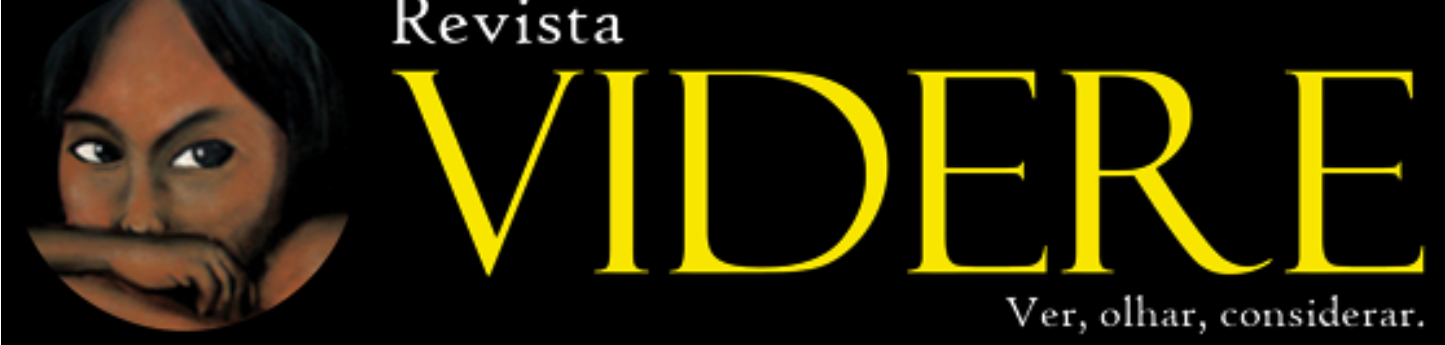

\section{A integração fronteiriça e o papel dos governos subnacionais no Mercosul: o caso Codesul-Crecenea d}

\section{Cross-border integration and the role of subnational governments in Mercosul: the case of Codesur-Crecenea}

\author{
Arthur Pinheiro de Azevedo Banzatto \\ Doutorando em Relações Internacionais (UFSC) \\ Universidade Estadual de Mato Grosso do Sul (UEMS) \\ Naviraí, Mato Grosso do Sul, Brasil \\ E-mail: arthur.banzatto@gmail.com
}

Resumo: O presente trabalho tem como objetivo analisar a fronteira como um espaço de integração política, econômica e social, com ênfase na atuação internacional dos governos subnacionais fronteiriços. Primeiramente, busca-se identificar as contribuições da História, da Geopolítica e do Direito na definição do conceito de fronteira, destacando o seu caráter polissêmico. A partir de então, busca-se compreender a fronteira sob a perspectiva das Relações Internacionais, identificando-a como um fator que contribui para a atuação externa dos governos subnacionais, que passam a desenvolver estratégias de cooperação fronteiriça com seus vizinhos estrangeiros, inserindo os interesses locais das áreas de fronteira no âmbito dos processos de integração regional. Por fim, a parceria Codesul-Crecenea é utilizada como estudo de caso para identificar como o fenômeno estudado se desdobra no plano empírico no contexto do Mercosul.

Palavras-chave: Integração Fronteiriça. Fronteira. Governos Subnacionais. Mercosul. Codesul-Crecenea.

\begin{abstract}
This paper aims at analyzing the frontier as a space for political, economic and social integration, with emphasis on the international performance of transborder subnational governments. Firstly, we seek to identify the contributions of History, Geopolitics and Law in the definition of the concept of frontier (border), highlighting its polysemic character. From then on, we seek to understand the frontier (border) from an international perspective, identifying it as an important factor for the external action of subnational governments, which develop strategies for transborder cooperation with their foreign neighbors, inserting the local interests of the frontier areas into the regional integration processes. Finally, the CodesulCrecenea partnership is used as a case study to identify how the studied phenomenon unfolds empirically in the context of Mercosur.
\end{abstract}

Keywords: Cross-Border Integration; Frontier (Border); Subnational Governments; Mercosur;Codesur-Crecenea.

Data de recebimento: $29 / 04 / 2020$

Data de aprovação: 18/06/2020

Revista Videre, Dourados, v. 12, n. 23, p. 60 a 79, jan./abr., 2020. 


\section{Introdução}

A partir de uma discussão teórica a respeito do conceito de fronteira e seus diferentes significados, 0 presente trabalho busca, inicialmente, contextualizar os debates existentes a partir de uma perspectiva interdisciplinar à luz da História, da Geografia, do Direito e das Relações Internacionais. Dentre as diversas concepções de fronteira, prioriza-se a de fronteira como fator de integração e de interpenetração mútua (MACHADO, 1998) e de "fronteira-interface" (MONDARDO, 2018).

Posteriormente, busca-se demonstrar que, nas regiões de fronteira, as dinâmicas de integração social e econômica entre os povos fronteiriços acabam transcendendo as linhas de fronteira impostas pelos Estados. Esses processos acabam transbordando para a esfera pública, fazendo surgir também iniciativas de integração política entre os governos subnacionais fronteiriços.

Argumenta-se que a globalização, ainda que não tenha eliminado as fronteiras nacionais entre os Estados, possibilitou o surgimento de novos fenômenos como a paradiplomacia, na qual os governos subnacionais buscam uma atuação internacional mais autônoma em relação ao governo central através de parcerias com atores externos. Nesse contexto, a fronteira é considerada como um fator geográfico que contribui para a paradiplomacia que, diante da proximidade entre os atores envolvidos, se desenvolve em sua modalidade transfronteiriça (DUCHACEK, 1990).

Por fim, utiliza-se a parceria Codesul ${ }^{1}-$ Crecenea $^{2}$ entre governos subnacionais brasileiros e argentinos como estudo de caso para analisar como o fenômeno estudado se desdobra no plano empírico, identificando as práticas de cooperação fronteiriça entre os atores envolvidos.

\section{A fronteira e seus múltiplos significados}

O conceito de fronteira é objeto de intensas discussões acadêmicas nas diversas áreas das Ciências Humanas, como História, Geografia, Direito, Relações Internacionais e correlatas. O seu caráter polissêmico faz com a fronteira possa ser compreendida a partir de diferentes dimensões - política, econômica e cultural e abordagens teóricas.

\subsection{Dimensão Histórico-Cultural}

No campo da História, importantes estudos consideram a fronteira não como um espaço geográfico em si, mas como um locus dinâmico de defrontação entre paisagens, populações, hábitos, instituições, técnicas e idiomas heterogêneos. Essa defrontação pode assumir características de integração e/ou de conflito,

\footnotetext{
1 O CODESUL existe desde 1961, quando os estados do Rio Grande Sul, Santa Catarina e Paraná assinaram um convênio criando, além do referido Conselho, o Banco Regional de Desenvolvimento do Extremo-Sul (BRDE) com o intuito de solucionar históricos problemas de desequilíbrio regional no país. O Mato Grosso do Sul foi incorporado em 1992. Além de atuar como um foro para ações coordenadas por parte dos quatro estados participantes, o órgão busca a integração e a cooperação com governos subnacionais de outros países fronteiriços, como no caso das províncias argentinas (IPPOLITO, 2018; BANZATTO, 2015; PRADO, 2013).

2 A CRECENEA-Litoral é um arranjo institucional criado em 1984 pelas províncias argentinas de Entre Rios, Santa Fe, Corrientes, Misiones, Chaco e Formosa com o objetivo de propor e difundir políticas comuns para fomentar as exportações da região, a integração dos setores produtivos regionais, a integração fronteiriça com os países vizinhos e a participação ativa nas decisões nacionais em matéria de comércio internacional que afetassem suas capacidades locais (IPPOLITO, 2018; BANZATTO, 2015; PRADO, 2013).
} 
dependendo de cada contexto e da perspectiva teórica adotada a respeito das relações sociais entre o Eu e o Outro.

Nessa lógica, o historiador norte-americano Frederick Turner identifica a fronteira como "o pico da crista de uma onda - o ponto de contato entre o mundo selvagem e a civilização" (KNAUSS, 2004, p. 24), com o intuito de analisar o fenômeno da "Marcha para o Oeste" nos EUA. Para o autor, a expansão da fronteira norteamericana, além de representar uma crescente autonomia em relação à Inglaterra (KNAUSS, 2004, p. 42), contribuiu também para a criação do mito fundador do pioneiro, do homem de fronteira que, inspirado pela vontade divina, construiria uma nova nação livre, moderna e democrática. Essa nova nação seria superior tanto em relação ao velho mundo europeu quanto, principalmente, em relação às sociedades indígenas que ali viviam, consideradas como atrasadas, selvagens e subalternas.

Em fins do século XIX, surgem novas disposições teóricas sobre os significados de fronteira, com o norte-americano Frederick Jackson Turner (1893), são pesquisas fundamentadas nas conquistas do oeste norte-americano. A tese de fronteira de Turner se difundiu por quase meio século como um modelo universal da compreensão da fronteira, influenciando a academia norteamericana e mundial, bem como formando redes de pesquisas correlatas à sua, seja para professar suas disposições, seja para criticá-las. Na primeira metade do século XX, no Brasil, aparecem escritos importantes, que não se vinculavam ao modelo propagado pelo IHGB, mas ao que parece - são tributários da tese de Turner (BALLER, 2014, p. 25).

No Brasil, ainda que não faça uma apologia à ideologia da expansão fronteiriça como Turner, o historiador Sérgio Buarque de Holanda, em sua obra clássica "Caminhos e Fronteiras", também utiliza de uma perspectiva da fronteira enquanto objeto em movimento para analisar a expansão territorial promovida pelos bandeirantes no contexto da colonização do Brasil. Para o autor, as interações entre o conhecimento adquirido na natureza pelos povos indígenas e as técnicas europeias trazidas pelo homem branco produziram elementos culturais simbióticos que resultaram na formação dos sertanistas e roceiros contemporâneos. Dessa forma, mesmo diante de um contexto mais amplo de dominação dos conquistadores europeus sobre os conquistados nativos, é possível identificar vínculos de comunicação, mestiçagem e aprendizado mútuos entre os dois povos, cuja influência repercute até os dias atuais em práticas como cartografia, locomoção, alimentação e exploração de recursos naturais (HOLANDA, 1994).

\subsection{Dimensão Geopolítica}

$\mathrm{Na}$ Geografia e, sobretudo na Geopolítica, o conceito de fronteira esteve tradicionalmente associado à sua origem etimológica do latim "in front", que significa aquilo que está na frente, referindo-se às margens ou limites que separam dois objetos, como os Estados, por exemplo (MONDARDO, 2018, p. 36). Desde os trabalhos do geógrafo alemão Friedrich Ratzel no final do século XIX, o tema das fronteiras é essencial para a análise das relações entre o Estado-nação soberano e o seu respectivo território, das relações bilaterais entre os Estados e das forças de integração ou de separação que ali emergem (COSTA, 1992, p. 291).

Na visão de Ratzel, a dimensão política da fronteira, que define os limites do exercício do poder soberano do Estado moderno, é definida a partir de uma "fronteira-linha" (border) abstrata que pode ser desenhada e 
medida entre os países. Esta, por sua vez, é complementada por uma "fronteira-zona" (frontier) ${ }^{3}$, essencialmente indeterminada e flexível, que representa a materialidade da fronteira como uma área de disputa, expansão territorial e tensão política entre os Estados (MONDARDO, 2018, p. 37-38).

A respeito do tradicional debate geográfico em torno da distinção entre fronteiras naturais e artificiais, inicialmente levantado pelo geógrafo francês Camille Vallaux em 1911, Costa (1992, p. 291) e Mondardo (2018, p. 38) o identificam como sendo superado pelo fato de que toda fronteira representa uma demarcação política e, portanto, historicamente construída. No entanto, autores contemporâneos como o geógrafo norte-americano Robert Kaplan ainda consideram relevante essa distinção.

Kaplan (2013) critica a existência de fronteiras artificiais, classificadas como arbitrárias pelo fato de derivarem exclusivamente da ação política, a exemplo da Alemanha dividida pelo Muro de Berlim. Nesses casos, argumenta-se que a tendência seria o triunfo das forças de unificação, pois "[...] o mais provável é que as forças da cultura e da geografia prevaleçam algum momento. Uma fronteira criada pelo homem que não coincide com uma zona de fronteira natural é algo particularmente vulnerável" (KAPLAN, 2013, p. XIX).

Nesse aspecto, portanto, as fronteiras artificiais estariam mais propensas às dinâmicas de integração através de práticas sociais e econômicas entre os povos fronteiriços que muitas vezes transcendem as linhas de fronteira impostas pelos Estados. Como exemplo dessas práticas, podemos mencionar a formação de arranjos produtivos locais binacionais; o compartilhamento de serviços públicos e de obras de infraestrutura; a circulação de bens e serviços; o deslocamento de mão de obra; entre outras.

Atualmente, com base na evolução dessa discussão, é importante estabelecer uma distinção clara entre limite e fronteira. Nesse aspecto, destaca-se que "o limite é abstrato e invisível, fruto de um tratado jurídico internacional ou delimitação" (ALBUQUERQUE, 2010, p. 35), que atua como um "fator de separação, pois separa unidades políticas soberanas e permanece como um obstáculo fixo" (MACHADO, 1998, p. 42).

A fronteira, por sua vez, seria uma faixa ou região entre países que forma um espaço amplo de relações sociais que ultrapassam os limites políticos, cuja extensão varia de acordo com cada país ${ }^{4}$ (ALBUQUERQUE, 2010, p. 35). Nesse sentido, "a fronteira pode ser um fator de integração, na medida que for uma zona de interpenetração mútua e de constante manipulação de estruturas sociais, políticas e culturais distintas" (MACHADO, 1998, p. 42).

\footnotetext{
${ }^{3}$ Essa distinção, além de teórica, possui repercussões importantes na língua inglesa, em que a palavra "border" é utilizada com o sentido de "fronteiralinha" e a palavra "frontier" com o sentido de "fronteira-zona".

${ }^{4}$ No Brasil, por exemplo, a Constituição Federal de 1988 estabelece em seu artigo 20, § $2^{\circ}$, que: "A faixa de até cento e cinqüenta (sic) quilômetros de largura, ao longo das fronteiras terrestres, designada como faixa de fronteira, é considerada fundamental para defesa do território nacional, e sua ocupação e utilização serão reguladas em lei.
} 
Essa perspectiva vai ao encontro do conceito de "fronteira-interface" proposto por Mondardo (2018, p. 69) no sentido de reconhecer que a fronteira "além de dividir também une, integra, transmite, hibridiza, 'deixa passar' " (MONDARDO, 2018, p. 28), tornando-se um "espaço de passagem que incita o movimento contínuo de pessoas, mercadorias e informações" (MONDARDO, 2018, p. 68).

A partir dessa leitura, compreende-se a fronteira como um espaço de integração política, econômica e social, a partir dos fluxos e interesses comuns que surgem nas faixas limítrofes dos países fronteiriços, merecendo também ser analisada sob a perspectiva internacional.

\subsection{Dimensão Jurídica}

Para o Direito, de forma geral, a fronteira representa os limites territoriais do exercício da jurisdição e do poder soberano do Estado, que, desde a celebração dos Tratados de Paz de Westphalia, em 1648, passou a representar a expressão máxima do poder e a monopolizar o uso legítimo da força dentro de seu respectivo território.

De acordo com Bobbio (1998), o conceito clássico de soberania surge no final do século XVI, junto com a formação do Estado moderno, para caracterizar a autoridade suprema que, dotada do monopólio da força sobre determinada população dentro de determinado território, unificava e concentrava o poder político. O soberano, único centro de poder, era o responsável por unificar os súditos de seu reino para a defesa do território nacional contra os inimigos estrangeiros.

Inicialmente utilizada para descrever e legitimar o Estado absolutista e centralizador que substituía a forma de organização política fragmentada e descentralizada da Idade Média, o conceito de soberania foi se ampliando para abranger outras formas de governo em que o poder seria entregue a uma assembleia, adequando-se ao advento do constitucionalismo, do parlamentarismo e da democracia. Bobbio, no entanto, adverte para o fato de que o conceito clássico de soberania não é mais adequado para compreender o Estado contemporâneo diante de suas mudanças internas e da nova configuração do sistema internacional.

No nosso século, o conceito político-jurídico de Soberania entrou em crise, quer teórica quer praticamente. Teoricamente, com o prevalecer das teorias constitucionalistas; praticamente, com a crise do Estado moderno, não mais capaz de se apresentar como centro único e autônomo de poder, sujeito exclusivo da política, único protagonista na arena internacional. Para o fim deste monismo contribuíram, ao mesmo tempo, a realidade cada vez mais pluralista das sociedades democráticas, bem como o novo caráter dado às relações internacionais, nas quais a interdependência entre os diferentes Estados se torna cada vez mais forte e mais estreita, quer no aspecto jurídico e econômico, quer no aspecto político e ideológico (BOBBIO, 1998, p. 11871188).

Para os fins do presente trabalho, dentre os poderes soberanos juridicamente constituídos do Estado, destaca-se o da supremacia da Constituição Federal, que delimita as competências da União e das suas respectivas unidades federadas nos casos em que o modelo federativo é adotado (BOBBIO, 1998, p. 1184).

Nas federações, a soberania pertence única e exclusivamente ao Estado Federal enquanto representante da nação, sendo suas unidades dotadas apenas de autonomia, um poder limitado que Ihes garante a capacidade de auto-organização, autogoverno, autoadministração e legislação própria com base no que é previsto pela Constituição Federal de cada país. 
Apesar da distribuição de competências variar de acordo com o que estabelece a Constituição de cada Estado Federal, as competências referentes à política externa e militar permaneceriam restritas somente à União, segundo a teoria federalista clássica. Deste modo, o monopólio da política externa e militar pela União é considerado pela doutrina majoritária do federalismo como uma característica fundamental de uma federação, fazendo com que ela se diferencie de uma confederação (PRAZERES, 2004; BOBBIO, 1998; DUCHACEK, 1970).

A atribuição ao Governo federal do monopólio das competências relativas à política externa e militar permite eliminar fronteiras militares entre os Estados, de modo que as relações entre os Estados perdem o caráter violento e adquirem um caráter jurídico e todos os conflitos podem ser resolvidos perante um tribunal (BOBBIO, 1998, p. 481).

Ressalta-se, no entanto, que essa perspectiva do federalismo clássico lida com os conceitos de política externa e de relações internacionais sob uma perspectiva restrita, centrada em temas de segurança e defesa nacional. No entanto, a ascensão de temas relativos às questões socioeconômicas no contexto da globalização e da integração regional permitiu a inserção também dos governos subnacionais das unidades federadas nas relações internacionais.

$\mathrm{Na}$ Constituição Federal da República Federativa do Brasil, o monopólio da União em assuntos internacionais está expresso nos seguintes artigos:

Art. 21. Compete à União: I - manter relações com Estados estrangeiros e participar de organizações internacionais; Art. 84. Compete privativamente ao Presidente da República: [...]; VII - manter relações com Estados estrangeiros e acreditar seus representantes diplomáticos; VIII - celebrar tratados, convenções e atos internacionais, sujeitos a referendo do Congresso Nacional; [...]. Art. 49. É da competência exclusiva do Congresso Nacional: I - resolver definitivamente sobre tratados, acordos ou atos internacionais que acarretem encargos ou compromissos gravosos ao patrimônio nacional; [...].

Ao contrário de países como a Argentina, a Alemanha, a Áustria e a Bélgica, onde as ações externas dos governos não centrais são constitucionalmente reconhecidas, a paradiplomacia no Brasil não possui previsão constitucional expressa, sendo que a Constituição da República Federativa do Brasil de 1988 atribui somente à União a competência para relacionar-se com Estados estrangeiros. Dessa forma, compete ao Presidente da República acreditar seus representantes diplomáticos e celebrar os tratados, convenções e atos internacionais, que deverão ser referendados no plano interno pelo Congresso Nacional.

Outro importante dispositivo constitucional que interessa ao presente trabalho é o Art. $20, \S 2^{\circ}$, o qual estabelece o conceito de faixa de fronteira e a sua extensão:

A faixa de até cento e cinqüenta (sic) quilômetros de largura, ao longo das fronteiras terrestres, designada como faixa de fronteira, é considerada fundamental para defesa do território nacional, e sua ocupação e utilização serão reguladas em lei (grifo nosso) (BRASIL, 1988).

No Brasil, existem 588 municípios localizados na faixa de fronteira, distribuídos em onze estados, dentre os quais 29 são cidades gêmeas e seis delas são conurbadas ${ }^{5}$. Desse modo, existe uma diferença conceitual entre a faixa de fronteira (150 km de distância da linha para dentro) e a linha de fronteira (demarcação do limite

\footnotetext{
5 "As cidades gêmeas conurbadas são aquelas em que a fronteira não é física (montanha, rio), mas é uma linha imaginária, geralmente traçada por uma rua. A linha que as divide, mesmo que seja politicamente bem demarcada, é móvel e borrada pela movimentação de bens e pessoas" (DESIDERA NETO; PENHA, 2016, p. 36).
} 
entre os países), conceitos jurídicos, para a região de fronteira, que se refere às dinâmicas sociais, econômicas e culturais que se desenvolvem no território fronteiriço (DESIDERA NETO; PENHA, 2016, p. 36).

Como o próprio texto constitucional ressalta, a questão fronteiriça é frequentemente tratada pelo Direito brasileiro pela lógica da defesa e da segurança nacional, considerando a fronteira não como um espaço de integração, mas sim de perigo e ameaça à soberania estatal, principalmente diante de práticas criminosas como o tráfico de drogas e o contrabando.

(...) ainda quando se pretendesse que "zona de fronteira" tem que ter necessariamente o mesmo sentido de "faixa de fronteira" que o art. $20, \S 2^{\circ}$, da Constituição considera fundamental para a defesa do território nacional, devendo sua ocupação e utilização ser reguladas em lei, é evidente que a lei poderá dar tratamento diferenciado a áreas situadas nesta "faixa de fronteira" em razão até da avaliação da necessidade de povoamento, para fins de defesa nacional, em umas e não em outras a justificar, ou não, a concessão de benefícios para a sua ocupação e utilização, ocupação e utilização essas que, por isso mesmo, foram deixadas para ser reguladas por lei (SUPREMO TRIBUNAL FEDERAL, 2003).

A associação entre fronteira e área de risco também se mostra evidente na legislação infraconstitucional, a exemplo da Lei 8.112/1990 (Lei do Servidor Público), que em seu artigo 71 estabelece adicional de atividade penosa aos servidores em exercício em zonas de fronteira ${ }^{6}$.

A discussão jurídica a respeito da competência sobre o controle dos fluxos fronteiriços foi destaque recentemente, em 2018, no imbróglio envolvendo a tentativa do governo de Roraima de fechar a fronteira do estado com a Venezuela ou limitar a entrada de venezuelanos no Brasil. Na ocasião, o caso chegou ao STF e a ministra Rosa Weber decidiu que o fechamento da fronteira era inconstitucional e violava tratados internacionais ratificados pelo Brasil, reforçando a competência da União para legislar e deliberar sobre o tema.

A teor do art. 22, XV, da Constituição da República, compete privativamente à União legislar sobre "emigração e imigração, entrada, extradição e expulsão de estrangeiros" e, nos moldes do art. 21, XXII, da CF, compete à União a execução do serviço de polícia de fronteiras, inserido, pelo art. 144, $\S 1^{\circ}$, III, da CF, por sua vez, entre as atribuições da polícia federal. Dispõe, ainda, o art. 91, § 1ำ III, da CF sobre a competência do Conselho de Defesa Nacional para propor critérios e condições de utilização de áreas indispensáveis à segurança do território nacional, e opinar sobre seu efetivo uso, especialmente na faixa de fronteira (SUPREMO TRIBUNAL FEDERAL, 2018).

Mesmo diante dessa decisão, acertada em nosso entendimento, os governos subnacionais desempenham diversas iniciativas de relações internacionais transfronteiriças, sejam elas formalizadas ou não. A seguir, buscaremos compreender como esse fenômeno se desdobra no plano empírico.

\section{Fronteiras e relações internacionais}

$\mathrm{Na}$ área de Relações Internacionais, a percepção sobre a fronteira apresenta diferentes características a depender do marco teórico utilizado, variando desde a ênfase na defesa nacional e na securitização das regiões fronteiriças por parte dos teóricos realistas, até a ênfase na interdependência e na cooperação entre os atores fronteiriços por parte dos teóricos liberais (SCHERMA, 2012).

\footnotetext{
${ }^{6}$ Art. 71. O adicional de atividade penosa será devido aos servidores em exercício em zonas de fronteira ou em localidades cujas condições de vida o justifiquem, nos termos, condições e limites fixados em regulamento.
} 


\subsection{A globalização e o mito da superação das fronteiras}

Sobretudo a partir dos anos 1990, no auge do fenômeno da globalização que passa a pautar o debate acadêmico, emergem teses ultraliberais segundo as quais a globalização provocaria uma espécie de "desnacionalização" das economias através do estabelecimento de redes transnacionais de produção, comércio e finanças (HELD, et al, 1999). Como consequência, haveria um fenômeno de "retração do Estado" (STRANGE, 1996, p. 4) ou até mesmo o do seu fim "a partir do desenvolvimento de uma economia global realmente sem fronteiras" (OHMAE, 1996, p. 23).

Essas teses, no entanto, parecem não ter se concretizado no plano empírico. Conforme demonstrado por Rodrik (2000, p. 178), diversas pesquisas sobre o tema revelam que a integração econômica internacional permanece notavelmente limitada pelas fronteiras nacionais, que possuem um efeito de retração nos níveis de comércio em virtude das diferentes taxas de câmbio e legislações entre os países.

Nesse aspecto, ainda possui grande relevância prática a ideia de "fronteira política", como bem aponta Baller (2014, p. 59), materializado pelos órgãos estatais que controlam os fluxos fronteiriços:

A fronteira política é entendida enquanto materialidade da fronteira, nessa concepção, as leis e a nação aparecem de forma a negociar a situação de fronteira para as pessoas em trânsito entre países e nos espaços limítrofes. E responsável por aproximá-las ou separá-las de seu interesse em ter mobilidade nesses espaços. Á fronteira política é formada por amplo aparato do Estado como Polícia Federal, Ministérios de Relações Exterior e Interior, diretórios centrais de recepção, tramitação e expedição de documentos, entre outros órgãos que acabam operacionalizando as funções para o Estado [...] A concepção política acerca da fronteira é responsável por delimitar a atuação desses órgãos e em consequência a legalidade que a própria fronteira exige. Não é raro ocorrer demandas com vistas a garantir a paz nesses locais, por meio de denúncias sobre perigo ou fatos extraordinários ligados aos limites dos países. A partir daí evocam- -se os velhos jargões sobre a necessidade de garantir a segurança nacional, mobilizam contingentes, criam leis e tratados, fecham temporariamente locais de passagem, atuam com maior rigor na fiscalização e circulação de bens, mercadorias e pessoas (BALLER, 2014, p. 59).

Em nosso entendimento, é possível reconhecer a existência de uma "difusão de poder" (NYE, 2010, p. 83) que estaria partindo do Estado em direção a novos atores, como corporações transnacionais, governos subnacionais e instituições internacionais sem, no entanto, negar a relevância do poder coercitivo estatal no controle, ou ao menos na regulação, dos fluxos de mercadorias, capitais e pessoas entre suas fronteiras. Menciona-se, por exemplo, a fixação de políticas migratórias que restringem a circulação de mão-de-obra, o estabelecimento de acordos regionais e o controle do acesso ao seu mercado interno através de tarifas, sanções, manipulação das taxas de câmbio e criação de carteis (NYE, 2010, p. 49).

Essa nova dinâmica do papel do Estado é bem sintetizada por Mondardo:

Embora o papel dos Estados nacionais esteja mudando, ele ainda participa das mais variadas escalas e esferas da sociedade com fundamental capacidade de intervenção, regulação e mediação no processo de acumulação do capital. Se, de um lado, o Estado se modificou pela fragilização de várias de suas no tratamento de questões sociais [...] alarga-se a sua função de permitir e criar condições para a fluidez e circulação das mercadorias na esfera da economia neoliberal (MONDARDO, 2018, p. 32).

Assim, a maior permeabilidade das fronteiras diante das transformações políticas, econômicas e sociais causadas pela globalização, ainda que não represente uma ameaça real à soberania do Estado, possibilita o surgimento de novas práticas, como a atuação internacional de governos subnacionais - também conhecidos 
como governos não centrais ou governos regionais/locais (estados-membros, províncias, departamentos e municípios) - historicamente restringidos ao exercício de competências domésticas de interesse local.

\subsection{A atuação externa dos governos subnacionais fronteiriços}

No campo teórico, diferentes conceitos, como os de paradiplomacia, diplomacia federativa e cooperação descentralizada, foram desenvolvidos e utilizados para explicar e caracterizar o fenômeno das ações internacionais dos governos subnacionais. Em geral, a opção pelo conceito de paradiplomacia reflete a perspectiva dos atores subnacionais, que possuem interesses locais próprios e buscam uma atuação internacional mais autônoma em relação ao governo central (DUCHACEK, 1990; SOLDATOS, 1990; RODRIGUES, 2008). Em contrapartida, conceitos como diplomacia federativa (PRAZERES, 2004; VIGEVANI, 2006) e cooperação descentralizada (RODRIGUES, 2008; SALOMÓN, 2012), sobretudo no Brasil, refletem a perspectiva dos governos centrais, que buscam coordenar, monitorar e/ou controlar essas ações, para evitar conflitos entre o interesse nacional e os interesses locais.

O elemento fronteiriço é apontado por Soldatos (1990, p. 48-49) e Duchacek (1990) como importante determinante da paradiplomacia, uma vez que a proximidade geográfica e demográfica, as afinidades culturais e as complementariedades econômicas ajudam a promovê-la.

No Brasil, o Rio Grande do Sul representa uma referência importante de paradiplomacia transfronteiriça no contexto da integração regional, com a criação da Secretaria Especial para Assuntos Internacionais (SEAI), em 1987, considerada a primeira secretaria estadual destinada a lidar com assuntos internacionais no país, durante o governo de Pedro Simon (1987-1990) (SEITENFUS, 1994; NUNES, 2005).

Dentre as iniciativas desenvolvidas, destaca-se a articulação da aproximação dos estados brasileiros da região sul do Brasil com as províncias fronteiriças do nordeste argentino, através da realização de diversos encontros envolvendo os governos estaduais e as prefeituras dos municípios fronteiriços através de Comitês de Fronteira (SEITENFUS, 1994).

Faz-se mister destacar aqui o apontamento feito por Albuquerque (2010, p. 50) de que essas regiões, mesmo pertencendo a Estados distintos, apresentam processos históricos, sociais e culturais em comum. Tanto o nordeste argentino quanto o sul brasileiro compunham "uma única região" que inicialmente se constituiu como área das missões jesuíticas e, a partir dos Séculos XIX e XX, como frentes extrativistas de erva-mate que receberam forte imigração europeia. Esse elemento reforça a tese de Kaplan (2004) de que as "fronteiras artificiais" tendem a tornar-se mais vulneráveis diante das forças de integração que ali emergem.

Outro ponto em comum entre eles é a distância dos centros políticos (Brasília e Buenos Aires), o que gerou, historicamente, uma percepção de omissão por parte dos respectivos governos centrais diante dos problemas específicos da região. A paradiplomacia transfronteiriça, portanto, passa a ser vista como uma alternativa a essa omissão (PRADO, 2013; COLACRAI; ZUBELZU, 2004; SEITENFUS, 1994).

Ao mencionar estudos na área de "cooperação subnacional" em regiões de fronteira, Scherma (2012, p. 127) nos revela que: "[...] são relativamente poucos aqueles que os relacionam às políticas nacionais, 
interpretando-os mais como uma forma individual de fuga de uma cooperação oficial nacional lenta em busca de resultados mais rápidos".

Essa modalidade de paradiplomacia, portanto, busca atuar em questões envolvendo assuntos típicos das áreas de fronteira, como: o fluxo de pessoas e bens; a gestão de projetos comuns; a formação de arranjos produtivos locais binacionais; o compartilhamento de infraestrutura e serviços públicos; entre outros.

\section{0 caso da parceria Codesul-Crecenea}

A Parceria entre Conselho de Desenvolvimento e Integração do Sul (CODESUL) e a Comissão Regional de Comércio Exterior do Nordeste Argentino (CRECENEA-LITORAL) é destacada de forma bastante positiva pela literatura brasileira que aborda a questão da atuação internacional dos governos subnacionais. Considerada como uma "zona de cooperação sub-regional" (PRAZERES; 2004) ou um "modelo de diplomacia subnacional regional" (JUNQUEIRA, 2014), ela é destacada como a principal articulação de governos subnacionais dentro do Mercosul (PRADO, 2013, p. 89); a primeira iniciativa paradiplomática multilateral na América Latina e modelo para o estabelecimento de futuras parcerias (LESSA, 2007).

No entanto, essa aproximação política entre os estados brasileiros da região sul e as províncias fronteiriças do nordeste argentino não ocorreu de forma isolada, mas dentro de um contexto mais amplo de cooperação e integração bilateral no nível nacional entre Brasil e Argentina.

\subsection{O contexto internacional das relações bilaterais entre Brasil e Argentina}

$\mathrm{Na}$ segunda metade da década de 1980, marcada pela consolidação da globalização como um importante fenômeno do sistema internacional, o Brasil e a Argentina iniciaram um processo de aproximação que resultou na celebração de diversos acordos de cooperação (econômica e política) entre os dois países. Ambos os Estados passavam por processos de redemocratização e liberalização econômica, e buscavam superar algumas rivalidades que marcavam as relações entre eles. Nesse contexto, a cooperação entre Brasil e Argentina se intensificou - resultando em acordos e pactos de integração e cooperação econômica - que possibilitaram a criação do Mercosul, em 1991.

Inicialmente, a Declaração de Iguaçu (1985) destaca-se por formalizar o objetivo de integração econômica e política entre Brasil e Argentina. Na sequência, assinou-se a Ata para a Integração BrasileiroArgentina (1986), que resultou no Programa de Integração e Cooperação Econômica (PICE), cuja finalidade principal era fomentar um espaço econômico comum através da complementação da economia de ambos os países através da intensificação das relações comerciais entre eles.

No âmbito do PICE, foram assinados diversos protocolos complementares, dentre os quais se destaca o Protocolo Regional Fronteiriço n. 23 (1988), que buscava o desenvolvimento da região de fronteira entre Argentina e Brasil. Este protocolo destaca-se por ser o primeiro instrumento internacional, negociado e aprovado pelo Brasil, que reconhece a participação de governos subnacionais na política externa, fomentando a cooperação descentralizada fronteiriça entre Brasil e Argentina (PRADO, 2019, 2013; NUNES, 2005; SEITENFUS, 1994). 


\subsection{A formalização da parceria}

A partir do Protocolo Regional Fronteiriço n. 23 (1988), formalizou-se a parceria entre o Conselho de Desenvolvimento e Integração do Sul (CODESUL) e a Comissão Regional de Comércio Exterior do Nordeste Argentino (CRECENEA-LITORAL), agregando estados-membros brasileiros e províncias argentinas ao Grupo de Trabalho Permanente (GTP) vinculado à Comissão de Execução do Programa, composto pelas chancelarias de ambos países (IPPOLITO, 2018; JUNQUEIRA, 2014; PRADO, 2019, 2013). A iniciativa buscou ampliar a participação destes atores no processo de integração regional que estava sendo desenvolvido entre Brasil e Argentina e fortalecer o desenvolvimento econômico da região fronteiriça.

De acordo com Lessa (2007) e Seitenfus (1994), o Protocolo Regional Fronteiriço n. 23 garante a produção de efeitos legais aos compromissos assumidos entre os governos subnacionais do CODESUL e CRECENEA, o que não costuma ocorrer em outros casos de cooperação descentralizada, nos quais ainda predomina uma situação de informalidade por conta das restrições da Constituição Federal de 1988, que estabelece competências internacionais apenas para a União?.

Além do GTP, foram criados os Comitês de Fronteira nas cidades gêmeas de Foz do Iguaçu - Puerto Iguazú e Uruguaiana - Paso de Los Libres. Estes órgãos são compostos por autoridades locais e presididos por representantes consulares para debater temas socioeconômicos e problemas operativos de fronteira (SALOMÓN; NUNES, 2007; SEITENFUS, 1994). De acordo com Colacrai e Zubelzu (2004, p. 159), os comitês indicam a implementação de um esquema jurídico-político de cooperação descentralizada e integração fronteiriça para regular temas de interesse comum - desenvolvimento regional, educação, comércio, circulação de mercadorias, combate ao tráfico, entre outros.

Após um período em que foram realizadas reuniões esporádicas entre os governadores dos dois grupos sub-regionais, a Declaração de Paso de Los Libres (1995) promoveu um avanço institucional ao criar o Foro Permanente de Governadores do CODESUL-CRECENEA, conferindo formato institucional às reuniões, que passaram a ocorrer duas vezes por ano (JUNQUEIRA, 2014; MEDEIROS, 2008). De forma complementar, foram criados onze Grupos de Integração Temática ${ }^{8}$ (GIT's), compostos por representantes dos governos subnacionais (SALOMÓN; NUNES, 2007).

Para Medeiros (2008), as reuniões semestrais entre os governadores representam um ato político no qual os atores subnacionais reivindicam sua importância no processo de governança regional através de políticas públicas em áreas como educação, cultura, meio ambiente e transporte. No entanto, as reuniões técnicas e os encontros de governadores perderam força a partir de 2000 , com a eclosão da grave crise econômica argentina (SALOMÓN; NUNES, 2007).

\footnotetext{
7 Art. 21. Compete à União: I - manter relações com Estados estrangeiros e participar de organizações internacionais; Art. 84. Compete privativamente ao Presidente da República: [...]; VII - manter relações com Estados estrangeiros e acreditar seus representantes diplomáticos; VIII - celebrar tratados, convenções e atos internacionais, sujeitos a referendo do Congresso Nacional; [...]. Art. 49. É da competência exclusiva do Congresso Nacional: I resolver definitivamente sobre tratados, acordos ou atos internacionais que acarretem encargos ou compromissos gravosos ao patrimônio nacional; [...].

8 Os GITs eram os de Aspectos Fronteiriços (subgrupos Defesa Civil e Agricultura), Saúde, Educação, Cultura, Turismo, Meio Ambiente, Segurança, Infraestrutura (subgrupos Transporte, Comunicação e Gasoduto), Ciência e Tecnologia, Cooperação Técnica e Conselhos Profissionais.
} 
Em 2008, essas ações foram retomadas a partir de um contexto político mais favorável em diferentes níveis. No nível nacional, houve um encontro entre os presidentes Lula e Cristina Kirchner no dia 22 de fevereiro de 2008, em Buenos Aires, no qual foram reforçados os compromissos em fortalecer a cooperação e a integração bilateral entre os dois países. No nível local, destaca-se o protagonismo do estado do Rio Grande do Sul, então governado por Yeda Crusius (PSDB), que buscou se reaproximar das províncias argentinas enquanto esteve na presidência do CODESUL (2007-2008) (FERREIRA, 2015).

Deste modo, foi realizado, em 2008, o X Fórum de Governadores do CODESUL e do CRECENEALitoral, ocasião em que foi redigida a Carta de Porto Alegre ${ }^{9}$. Tal documento reforça o compromisso dos governos subnacionais na busca pelo aprofundamento da integração física e energética da região, pelo desenvolvimento econômico e social, pela preservação ambiental, pela integração cultural e turística e pelo fortalecimento do conceito de cidadania sul-americana.

\subsection{Esvaziamento e legado da parceria}

Apesar da longa trajetória percorrida, o X Fórum de Governadores em Porto Alegre foi o último ápice político da parceria institucional entre o CODESUL e o CRECENEA, que se encontra atualmente como um arranjo bastante fragilizado diante de sua prolongada inatividade política (CALDEIRA, 2019; IPPOLITO, 2018; FERREIRA, 2015).

Mesmo assim, esta parceria é apontada como uma importante forma de inserir os governos não centrais no processo de integração regional do Mercosul, influenciando politicamente o modus vivendi do bloco e promovendo sua democratização, mesmo diante dos limites impostos por seu caráter intergovernamental. Assim, cria-se uma espécie de governança regional, na qual os estados brasileiros e províncias argentinas se envolvem de forma conjunta em assuntos como infraestrutura, saúde, cultura, educação, turismo, meio ambiente, ciência e tecnologia, cooperação técnica e segurança (MEDEIROS, 2003; 2008).

De fato, trata-se de um importante marco para a cooperação descentralizada não apenas no plano político, conforme já relatado, como também no plano jurídico através da produção de efeitos legais aos compromissos assumidos no âmbito da cooperação descentralizada (LESSA, 2007; SEITENFUS, 1994).

O que parecia impossível restava conquistado; pela primeira vez na história de nossa política externa, o governo central admitia, formalmente, que estados da União exercessem, ainda que sob certas condições, atividades autônomas de caráter internacional. A partir da assinatura do Protocolo 23, nove estados e províncias dos dois países poderiam promover seus interesses externos mútuos sem se remeterem às chancelarias (SEITENFUS, 1994, p. 86).

Em um recente estudo de caso sobre o CODESUL-CRECENEA, Caldeira (2019, p. 92) destaca o seu legado positivo e as ações desenvolvidas ao longo dos seus mais de trinta anos de existência:

${ }^{9}$ Documento Disponível em: https://estado.rs.gov.br/integra-da-carta-de-porto-alegre. Acesso em 11 de dezembro de 2019. 
É importante destacar, todavia, que o CODESUL/CRECENEA-LITORAL trata-se de um projeto relativamente bem-sucedido; seus trinta anos de existência e uma série de ações e obras concretizadas sob seus auspícios não fazem mentir. Pontes, rodovias, programas de intercâmbio científico, cooperação técnica e ambiental constituem necessidades comuns que muitas vezes só foram possíveis materialmente devido a essa inflexível congruência de interesses dos estados federados brasileiros e províncias argentinas limítrofes. Nesse sentido, a pesquisa demonstrou que a iniciativa subnacional produziu impactos interessantes (CALDEIRA, 2019, p.92).

Assim como a criação de secretarias específicas para as relações internacionais nos governos estaduais e municipais, a parceria entre o CODESUL e CRECENEA é apontada por Vigevani (2006, p. 22) como um exemplo de institucionalização da paradiplomacia regional. Dentro dessa perspectiva, é possível inferir que esta iniciativa é influenciada pelos mesmos fatores domésticos que implicam na descontinuidade das ações desenvolvidas por estados-membros, províncias e municípios, fenômeno conhecido como stop and go (BUENO, 2010; MATSUMOTO, 2011; JUNQUEIRA, 2015). Diante de eventos como trocas de mandato, oscilações econômicas e político-partidárias, e até mesmo questões pessoais dos governadores, é comum que os órgãos criados para lidar com questões internacionais sejam esvaziados, reestruturados e até mesmo extintos ${ }^{10}$.

De acordo com Ippolito (2018, 2017), essa descontinuidade se deve a problemas estruturais da integração fronteiriça entre Brasil e Argentina no âmbito do Mercosul, entre eles: a falta de consciência social sobre as potencialidades do desenvolvimento local; a ausência de um sentimento de identidade fronteiriça comum entre as populações e, principalmente, a não incorporação da sociedade civil organizada em questões envolvendo a integração regional e fronteiriça, o que gera um déficit democrático e participativo que enfraquece o desenvolvimento da parceria CODESUL-CRECENEA.

Se constatou que por suas deficiências institucionais - sobretudo a existência de espaço formais para a participação dos cidadãos e da sociedade civil - o esquema de integração falhou em consolidar socialmente uma identidade que o âmbito público se tentanva impulssionar (IPPOLITO, 2018, p. 141, tradução nossa) ${ }^{11}$.

Ao versar sobre a integração regional no âmbito do Mercosul como um todo, essa crítica também é feita por França (2011, p. 336), quem argumenta que, apesar do aumento do interesse de outros atores pela política externa no contexto da integração regional, os processos envolvendo as principais negociações e tomadas de decisão foram estritamente conduzidos pelos presidentes e diplomatas, não envolvendo um amplo debate nacional que incorporasse os atores da sociedade civil.

Caldeira (2019), por sua vez, argumenta que o principal problema para o avanço da parceria tem sido a falta de um marco jurídico para o exercício da paradiplomacia, além da centralização por parte dos Estados Nacionais na condução das relações exteriores, restringindo a autonomia dos estados-membros e províncias

\footnotetext{
10 No Brasil, exemplos desse fenômeno são: Rio de Janeiro (1983 - 1990), Ceará (1995 - 2006) e Amapá (1995 - 2002) (BUENO, 2010; RODRIGUES, 2004). Na Argentina, o fenômeno também ocorre, sobretudo diante de crises como a de 2001, quando muitas administrações provinciais extinguiram os órgãos voltados para assuntos internacionais. Ao versar sobre a fragilidade desses órgãos, Paikin (2010, p. 47-48) afirma que geralmente são os primeiros a serem descartados em momentos de crise, pois a sociedade tem dificuldades para reconhecer a sua real utilidade.

11 Se ha constatado que por sus deficiencias institucionales -sobre todo la inexistencia de espacios formales para la participación ciudadana y de la sociedad civil- el esquema de integración falló en consolidar socialmente una identidad que desde el ámbito público se intentaba impulsar.
} 
para celebrarem acordos. Ademais, o autor também menciona a imposição unilateral de altos impostos alfandegários e a falta de incentivos fiscais e subsídios por parte dos respectivos governos centrais.

Entretanto, a paradiplomacia não está institucionalizada no Brasil, de modo que a condução do assunto pelos estados e municípios ainda padece de heterogeneidade. Como não há um modelo a ser seguido, diferem os enfoques e as formas de organização de acordo com os interesses e o perfil de cada região; além de, por vezes, até o partido político no poder determinar opções distintas Ao mesmo tempo, inexiste a regulamentação expressa da prática da diplomacia ad hoc no Brasil, o que traz ainda sérios empecilhos a uma atuação internacional ativa por partes das unidades federadas pátrias. [...] In casu, tal asserção ganha ainda mais relevância. Nesse sentido, é inegável que o que dificulta e retarda o avanço do CODESUL/CRECENEA-LITORAL, é a falta de autonomia de que persistem gozando, no Brasil e Argentina, estados e províncias. Inúmeros acordos firmados, sobretudo a partir do advento do Foro Permanente de Governadores, simplesmente esbarraram na burocracia dos governos federais respectivos, por vezes refratários às angústias e interesses locais. Nesse ensejo, não é à toa que, por ocasião de todas suas reuniões, o CODESUL/CRECENEA-LITORAL tenha ressaltado a necessidade do apoio e reconhecimento dos governos centrais brasileiro e argentino, além do próprio MERCOSUL (CALDEIRA, 2019, p. 90).

Ressalta-se, no entanto, que no âmbito específico da parceria CODESUL-CRECENEA, existe um entendimento segundo o qual todo o seu arranjo institucional foi desenvolvido sob o marco legal do Protocolo Regional Fronteiriço n. 23 (1988) que complementou o Programa de Integração e Cooperação Econômica (PICE) celebrado entre Brasil e Argentina.

Nesse sentido, houve o reconhecimento formal da paradiplomacia desenvolvida por parte dos governos subnacionais da região (LESSA, 2007; SEITENFUS, 1994). Em outras palavras, ainda que não exista um marco jurídico geral da paradiplomacia previsto expressamente na Constituição Federal da República Federativa do Brasil, o referido Protocolo representa uma espécie de "acordo guarda-chuva" (umbrella agreement) (SOLDATOS, 1990, p.38) que legitima a parceria em tela.

Considera-se, assim, que as conclusões apontadas por Caldeira (2019) e Ippolito (2018) destacam a necessidade de uma análise mais aprofundada sobre questão, pois, apesar da inatividade do Foro Permanente de Governadores do CODESUL-CRECENEA, é possível identificar outras iniciativas relevantes de paradiplomacia transfronteiriça nessa região, sobretudo no nível municipal através de Comitês de Fronteira e arranjos similares desenvolvidos em cidades-gêmeas, principalmente aquelas conurbadas ${ }^{12}$.

Nesse contexto, costuma-se alegar que as regiões de fronteira, de forma geral, e as cidades gêmeas, de forma específica, atuam como "laboratório da integração regional" (DESIDERA NETO; PENHA, 2016, p. 36), como um "locus propício para as ações de cooperação e para a inserção internacional dos governos subnacionais" (BANZATTO; PRADO, 2014, p. 20) e como dotadas de um papel de grande importância no processo de integração regional, muitas vezes atuando como uma região de vanguarda na cooperação transfronteiriça (CARNEIRO, 2019). Isso ocorre pelo fato de que as decisões tomadas no âmbito regional repercutem com maior intensidade na fronteira, onde existem dinâmicas transfronteiriças de interlocução econômica (comercial, trabalhista e financeira) e social (no âmbito das relações familiares e no

\footnotetext{
12 "As cidades gêmeas conturbadas são aquelas em que a fronteira não é física (montanha, rio), mas é uma linha imaginária, geralmente traçada por uma rua. A linha que as divide, mesmo que seja politicamente bem demarcada, é móvel e borrada pela movimentação de bens e pessoas (DESIDERA NETO; PENHA, 2016, p. 36).
} 
compartilhamento de serviços públicos de saúde e educação) que perpassam os limites territoriais impostos pelo Direito.

A título ilustrativo, o estudo de Desidera Neto e Penha (2016) sobre a Cartilha da Cidadania do Mercosul, documento editado em 2010 com o objetivo de normatizar questões do interesse dos cidadãos do bloco, identificou que das 59 iniciativas listadas ${ }^{13}$, apenas seis (10\%) não apresentavam maior impacto nas regiões de fronteira em comparação com o interior dos países e os grandes centros urbanos. Na conclusão, os autores destacam que "Estes números indicam que são poucas as decisões em que o impacto na fronteira não é maior, reforçando a ideia de que são espaços em que o monitoramento e a avaliação de políticas públicas de integração regional merecem maior atenção" (DESIDERA NETO; PENHA, 2016, p. 48).

Nas cidades gêmeas, onde as pessoas vivem diariamente a integração fronteiriça em sua plenitude, a questão se mostra ainda mais evidente. Tal fato é reconhecido não apenas pelo meio acadêmico, mas pelas próprias burocracias estaduais. Segundo documento intitulado "Plano de Desenvolvimento e Integração da Faixa de Fronteira/MS", elaborado pelo governo estadual do Mato Grosso do Sul, estado que possui oito cidades-gêmeas:

O meio geográfico que melhor caracteriza a Faixa de Fronteira é aquele formado pelas cidadesgêmeas. Esses adensamentos populacionais cortados pela linha de fronteira (seja esta seca ou fluvial, articulada, ou não, por obra de infraestrutura) apresentam grande potencial de integração econômica e cultural, assim como manifestações condensadas dos problemas característicos da fronteira, que aí adquirem maior densidade, com efeitos diretos sobre o desenvolvimento regional e a cidadania (GOVERNO DO ESTADO DE MATO GROSSO DO SUL, 2012, p. 13)

Na fronteira envolvendo o Mato Grosso do Sul (membro do CODESUL desde 1992) com o Paraguai, sobretudo no âmbito das cidades-gêmeas de Ponta Porã (MS) e Pedro Juan Caballero (PY), é possível identificar iniciativas de paradiplomacia transfronteiriça como o Parlamento Internacional Municipal (PARLIM); a Gestão Integrada da Bacia do Rio Apa (GIAPA); a Gestão Municipal e Comunitária no Serviço de Coleta e Disposição dos Resíduos Sólidos e o Projeto Urbal III - Línea Internacional, programa de revitalização urbana levada à cabo pelas prefeituras das cidades gêmeas de Ponta Porã - BR e Pedro Juan Caballero - PY com recursos da União Europeia (PRADO, 2019). Além destas, destaca-se também o Projeto CODESUL Fronteiras, para mapeamento e diagnóstico de todo tipo de violência que acomete as mulheres nas regiões fronteiriças dos estados-membros do CODESUL, apresentado na Comissão de Relações Exteriores e Defesa Nacional do Senado Federal no dia 11/07/2019 (SENADO FEDERAL, 2019).

Na fronteira com a Argentina, um caso relevante nesse sentido é o Consórcio Intermunicipal da Fronteira (CIF), formado pelos municípios de Barracão e Bom Jesus do Sul (Paraná), Dionísio Cerqueira (Santa Catarina) e Bernardo de Irigoyen (Misiones - Argentina). A formalização desse consórcio, que consta com Estatuto e inscrição no Cadastro Nacional de Pessoa Jurídica (CNPJ) ocorreu em 2009, um ano depois do X Fórum de Governadores em Porto Alegre (2008), considerado como o último ápice político da parceria institucional entre o CODESUL e o CRECENEA. Dentre os principais objetivos do consórcio, destaca-se a gestão conjunta da

\footnotetext{
13 "As iniciativas são divididas em doze categorias: i) circulação de pessoas e bens; ii) trabalho e seguridade social; iii) educação; iv) defesa do consumidor; v) apoio à produção e ao comércio; vi) correspondências e encomendas; vii) cooperação consular e jurídica; viii) direitos humanos; ix) integração cultural; $x$ ) aspectos sanitários e de saúde; xi) dimensão social e xii) temas diversos" (DESIDERA NETO; PENHA, 2016, p. 39).
} 
infraestrutura local, uma vez que os municípios em questão formam na prática um único tecido urbano (AGNES et al, 2013, p. 1.168).

Na fronteira do Paraná com a Argentina, o Comitê de Integração entre Foz do Iguaçu e Puerto Iguazú já realizou XXXV Reuniões Anuais, sendo a última em 2017, que contou com uma representante do Ministério das Relações Exteriores do Brasil e foi composta por oito mesas temáticas: comércio, turismo, migração, infraestrutura, planejamento urbano, educação, saúde e cultura (GOVERNO DO MUNICÍPIO DE FOZ DO IGUAÇÚ, 2017).

No Rio Grande do Sul, os Comitês de Integração Fronteiriça envolvendo municípios gaúchos que fazem fronteira com a Argentina (Uruguaiana - Paso de Los Libres ${ }^{14}$; São Borja - Santo Tomé15) continuam ativos, realizando reuniões e encontros que contam inclusive com representantes da SAF (Subchefia de Assuntos Federativos) da Presidência da República ${ }^{16}$, do Consulado Brasileiro e do Consulado Argentino (MENDES et al, 2019).

As cidades de Uruguaiana (RS) e Passo de Los Libres (ARG) já realizaram XIV encontros do Comitê de Integração Fronteiriça, ao passo que São Borja (RS) e Santo Tomé (ARG), apesar de terem formalizado seu Comitê de Fronteira apenas em 2018, já contam também com uma Câmara Legislativa Binacional (MENDES et al, 2019).

Na tríplice fronteira envolvendo Brasil, Argentina e Uruguai, foi publicado em 2019 um Memorando de Entendimento entre a República Federativa do Brasil, a República Argentina e a República Oriental Do Uruguai sobre a criação e o funcionamento do Comitê de Integração Fronteiriça Trinacional Barra Do Quaraí (Brasil), Monte Caseros (Argentina) e Bella Unión (Uruguai) com o objetivo de "receber demandas da população local e promover medidas que contribuam para o desenvolvimento social, econômico-comercial, cultural, científicotecnológico, sanitário, ambiental, turístico e esportivo da zona fronteiriça conformada pelas três cidades referidas" (BRASIL, 2019, Art. $1^{\circ}$ ).

De forma geral, todas essas iniciativas buscam promover a integração fronteiriça através da adoção conjunta de políticas públicas nas mais diversas áreas (educação, saúde, infraestrutura e comércio), como a criação de escolas fronteiriças e a promoção do intercâmbio universitário; a integração de ações e serviços de saúde na região de fronteira através de programas como o SIS Fronteiras; a construção de pontes e outras obras de infraestrutura para interligar as cadeias produtivas fronteiriças; a criação de lojas "free shop" para estimular o turismo de compras e fomentar o setor de serviços na fronteira; entre outros (CARNEIRO, 2019).

\footnotetext{
14 Maiores informações em: https://www.uruguaiana.rs.gov.br/noticia/view/4647/comite-de-fronteira-debate-temas-relacionados-a-integracao-do-brasile-argentina?fbclid=IwAR0gpk6fN0e3bBx67Wg3wwDOiighXG3S2sK95H55Lweyx4PDZ626n0OQZIk

${ }^{15}$ Maiores informações em: https://www.saoborja.rs.gov.br/index.php/ultimas-noticias/1449-sao-borja-e-santo-tome-formalizam-formacao-de-comite-deintegracao?fbclid=IwAR1G6mH ITThCCWKVLcwG4vZFgSG7FEWWgTIRgs6diRr1aRvinR9ZcStfMU

${ }^{16}$ Maiores informações em: http://www.portalfederativo.gov.br/noticias/destaques/saf-participa-de-comites-de-integracao-fronteirica-na-regiao-sul
} 


\section{Considerações Finais}

A partir dos conceitos e fatos analisados, conclui-se que a parceria entre o CODESUL e o CRECENEA nos revela um importante exemplo empírico de que a fronteira pode ser também um espaço que aproxima atores fronteiriços de diferentes países através de mecanismos formais e informais de integração.

Mesmo diante da fragilidade atual, a iniciativa é apontada como uma importante forma de inserir os governos não centrais fronteiriços no processo de integração regional do Mercosul, não apenas sendo influenciado por ele, mas também promovendo iniciativas próprias para lidar com questões locais. Assim, criouse uma espécie de "governança regional" (MEDEIROS, 2008), na qual os estados brasileiros e províncias argentinas se envolveram de forma conjunta em assuntos como infraestrutura, saúde, cultura, educação, turismo, meio ambiente, ciência e tecnologia, cooperação técnica e segurança.

Trata-se, portanto, de uma experiência pioneira que serve de exemplo para iniciativas similares em outras regiões fronteiriças, a exemplo do que já vem ocorrendo na fronteira entre o Brasil e seus vizinhos do Mercosul, sobretudo nas cidades-gêmeas através de iniciativas como Consórcios Intermunicipais e Comitês de Fronteira destinados a resolver problemas fronteiriços comuns.

Por fim, é importante ressaltar que, para evitar o enfraquecimento e a descontinuidade dessas ações, é imprescindível a inclusão não apenas das burocracias locais, mas também da sociedade civil organizada, agregando maior legitimidade às iniciativas e criando a noção de uma identidade fronteiriça entre os povos. Essa inclusão justifica-se principalmente pelo fato de que os cidadãos fronteiriços são aqueles que mais sofrem os impactos (positivos ou negativos) da integração regional.

\section{Referências}

AGNES, Juliane Sachser; MATTOS, Sandra Mara Matuisk; KLOZOVSKI, Marcel Luciano; STURM, Marlete Inês. Consórcio Intermunicipal da Fronteira (CIF): descrevendo as principais ações voltadas ao desenvolvimento regional a partir da perspectiva do poder público municipal. Rev. Adm. Pública, v. 47 , n. 5 , p. $1165-188$, set./out. 2013.

ALBUQUERQUE, J. L. C. A dinâmica das fronteiras: os brasiguaios na fronteira entre o Brasil e o Paraguai. São Paulo: Annablume, 2010.

BALLER, Leandro. Fronteira e Fronteiriços: a construção das relações socioculturais entre brasileiros e paraguaios (1954-2014). Curitiba; CRV, 2014.

\section{BANZATTO, A. P. A. A Inserção Internacional Dos Governos Não Centrais Brasileiros E}

Argentinos Em Perspectiva Comparada. Dissertação de Mestrado. Universidade de Brasília (UnB): Brasília, 2015.

BANZATTO, A. P. A.; PRADO, H. S. A. A paradiplomacia, a cooperação descentralizada e integração fronteiriça no Mercosul. Meridiano 47, v. 15, n. 141, p. 18 - 24, jan-fev, 2014.

BOBBIO, Norberto; MATTEUCCI, Nicola; PASQUINO, Gianfranco. Dicionário de Política, vol. I. 11 Ed. Brasília: Editora Universidade de Brasília, 1998.

BRASIL. Memorando de Entendimento entre a República Federativa do Brasil, a República Argentina e a República Oriental do Uruguai sobre a criação e o funcionamento do Comitê e 
Integração Fronteiriça Trinacional Barra Do Quaraí (Brasil), Monte Caseros (Argentina) e Bella Unión (Uruguai). Diário Oficial da União: Brasília, 2019. Disponível em:

http://www.in.gov.br/en/web/dou/-/memorando-de-entendimento-entre-a-republica-federativa-do-

brasil-a-republica-argentina-e-a-republica-oriental-do-uruguai-sobre-a-criacao-e-o-funcionamento-docomite-de-integracao-fronteirica-trinacional-barra-do-quarai-brasil-monte-caseros-argentina-e-bel. Acesso em: 28/04/2020.

BRASIL. Constituição da República Federativa do Brasil de 1988. Disponível em: http://www.planalto.gov.br/ccivil 03/Constituicao/Constituicao.htm. Acesso em :15 de abril de 2020.

CALDEIRA, Alberto Lunardelli. Codesul/Crecenea-Litoral: Aspectos de um Projeto da Paradiplomacia no Mercosul. Revista da Secretaria do Tribunal Permanente de Revisão do Mercosul, ano 7, n. 13, p. 77-94, mar., 2019.

CARNEIRO, Camilo Pereira. La Cooperación Transfronteria en las Ciudades Gemelas de la Frontera Sur de Brasil. Aldea Mundo, año 24, n. 47, p. 39-50, enero-junio 2019.

COLACRAI, Miryam; ZUBELZÚ, Graciela. Las vinculaciones externas y la capacidad de gestión internacional desplegadas por las províncias argentinas en la última década: una lectura desde las relaciones internacionales. In: VIGEVANI, Tullo et al (org.). A dimensão subnacional e as relações internacionais. São Paulo: EDUC, 2004.

COSTA, Wanderley Messias da. Geografia política e geopolítica. São Paulo, Edusp,1992.

DESIDERA NETO, Walter Antonio; PENHA, Bruno. As Regiões de Fronteira como Laboratório de Integração Regional no Mercosul. Boletim de Economia e Política Internacional (BEPI), n. 22, jan/abril de 2016, pp. 33 - 50. In: DESIDERA NETO; W.; PENHA, B.; MORAES, R. Mercosul e regiões de fronteira. Brasília: IPEA, 2016.

DUCHACEK, Ivo. Perforated sovereignties: towards a typology of news actors in international relations. In: SOLDATOS, Panayotes; MICHELMANN, Hans (Eds.). Federalism and International Relations: the role of subnational units. New York: Oxford University Press, 1990, p. 1-33.

FERREIRA, Bruno Guedes. A Paradiplomacia no Rio Grande do Sul (2007-2014): um comparativo das ações externas em diferentes posições político partidárias. I Seminário Internacional de Ciência Política Universidade Federal do Rio Grande do Sul, Porto Alegre, 2015.

GOVERNO DO ESTADO DE MATO GROSSO DO SUL. Plano de Desenvolvimento e Integração da Faixa de Fronteira/MS: Campo Grande, 2012.

GOVERNO DO MUNICÍPIO DE FOZ DO IGUAÇU. Comitê de Integração entre Foz do Iguaçu e Puerto Iguazú Discute Questões da Fronteira. Foz do Iguaçu: 2017. Disponível em: http://www.pmfi.pr.gov.br/noticia/?idNoticia=41767. Acesso em: 28/04/2020.

HELD, David et al. Global Transformations: Politics, Economics and Culture. Stanford: Stanford University Press, 1999.

HOLANDA, Sérgio Buarque de. Caminhos e Fronteiras. 3a ed. São Paulo: Cia das Letras, 1994.

JUNQUEIRA, Cairo Gabriel Borges. A Inserção Internacional dos Atores Subnacionais e os Processos de Integração Regional: Uma Análise da União Europeia e do Mercosul (Dissertação de Mestrado). Universidade de Brasília: Brasília, 2014. 
IPPOLITO, Daniel. Revisitando viejos esquemas de cooperación transfronteriza en el MERCOSUR: un análisis de la institucionalidad de CRECENEA y su proyección hacia los Estados del Sur de Brasil (CODESUL). Pampa, Santa Fe, n. 15, p. 9-29, jun. 2017.

IPPOLITO, Daniel. Revisitando viejos esquemas de cooperación transfronteriza en el MERCOSUR: un análisis de la institucionalidad de CRECENEA y su proyección hacia los Estados del Sur de Brasil (CODESUL). Pampa, Santa Fe, n. 15, p. 9-29, jun. 2017.

KAPLAN, Robert. A vingança da geografia: a construção do mundo geopolítico a partir da perspectiva geográfica. São Paulo, Campus, 2013.

KNAUSS. Paulo (org.). O significado da fronteira na história americana; e; O problema do oeste. In: Oeste americano: quatro ensaios de história dos Estados Unidos da América de Frederick Jackson Turner. Niterói - RJ: EdUFF, 2004, p. 23-69.

LESSA, José Vicente da Silva. Paradiplomacia no Brasil e no Mundo: o poder de celebrar tratados dos governos não centrais. Viçosa: Ed. UFV, 2007.

MACHADO, Lia Osório. Limites, Fronteiras, Redes. In: T.M.Strohaecker et al (org.). Fronteiras e Espaço Global. Porto Alegre: AGB, 1998.

MEDEIROS, Marcelo de Almeida. Legitimidade, Democracia e Accountability no Mercosul. RBCS, v. 23, n. 67, p. 51-69, junho, 2008.

MEDEIROS, Marcelo de Almeida. Dinâmica subnacional e lógica centro-periferia: os impactos do Mercosul na economia política dos estados de Pernambuco, Bahia, São Paulo e Rio Grande do Sul. Revista Brasileira de Política Internacional, Brasília, ano 49, n. 1, 2006.

MENDES, Larissa Zanela; CEOLIN, Lisianne Pintos Sabedra; COLVERO, Ronaldo Bernardino. Relações intermunicipais de fronteira: análise dos mecanismos de integração adotados pelas cidades gêmeas de São Borja (Brasil) e Santo Tomé (Argentina). Diálogo, Canoas, n. 40, p. 81-92, abr. 2019

MONDARDO, Marcos L. Fronteiras, e, Da transculturação à transterritorialidade: a emergência de outras cartografias. In: Territórios de trânsito: dos conflitos entre Guarani e Kaiowá, paraguaios e gaúchos à produção de multi/transterritorialidade na fronteira. Rio de Janeiro: Consequência, 2018, p. 27-127.

NUNES, Carmen Juçara da Silva. A paradiplomacia no Brasil: o caso do Rio Grande do Sul. Dissertação de Mestrado. Universidade Federal do Rio Grande do Sul: Porto Alegre, 2005.

NYE, Joseph. The Future of Power. Washington, DC: Public Affairs, 2010.

OHMAE, Kenichi. O Fim do Estado-nação: a ascensão das economias regionais. Rio de Janeiro: Campus, 1996.

PAIKIN, Damián. Integración Regional y Nuevos pactos Federales: El rol de los gobiernos subnacionales en el MERCOSUR (Tese de Doutorado). Universidad de Buenos Aires: Buenos Aires, 2010.

PAIKIN, Damián. Federalismo e integración regional: los vínculos de las provincias argentinas con el MERCOSUR. Revista Estudios en Relaciones Internacionales, n. 41, p. 131-148. Buenos Aires, 2011. 
PRADO, Henrique Sartori de Almeida. A cooperação descentralizada e a política para a fronteira no Brasil. Curitiba: Íthala, 2019.

PRADO, Henrique Sartori de Almeida. Inserção dos atores subnacionais no processo de integração regional: o caso do Mercosul. Dourados: Ed. UFGD, 2013.

PRAZERES, Tatiana Lacerda. Por uma atuação constitucionalmente viável das unidades federadas brasileiras ante os processos de integração regional. In: VIGEVANI, Tullo et al (org.). A dimensão subnacional e as relações internacionais. São Paulo: EDUC; Fundação Editora da UNESP; Bauru: EDUSC, 2004.

RODRIGUES, Gilberto Marcos Antonio. Relações internacionais federativas no Brasil. Revista Dados, Rio de Janeiro, v. 51, n. 4, p. 1015-1034, 2008.

RODRIK, Dani. How far will international integration go? Journal of Economic Perspectives, v.14, n.1, p. 177-186 2000.

SALOMÓN, Mónica. Em que medida é possível integrar a Cooperação Descentralizada na dimensão Sul-Sul da política externa brasileira? Revista Mural Internacional. Ano III - no 2, p. 9-15, 2012.

SALOMON, Mónica; NUNES, Carmen. A ação externa dos governos subnacionais no Brasil: os casos do Rio Grande do Sul e de Porto Alegre. Um estudo comparativo de dois tipos de atores mistos. Contexto int., Rio de Janeiro, v. 29, n. 1, 2007.

SCHERMA, Márcio Augusto. As Fronteiras nas Relações Internacionais. Revista Monções, v.1, n.1, p. 103-132, jan./jun., 2012.

SEITENFUS, Ricardo. Para uma nova política externa brasileira. Porto Alegre: Livraria do Advogado, 1994.

SENADO FEDERAL. 38ª Reunião da Comissão de Relações Exteriores e Defesa Nacional. Brasília: 2019. Disponível em: https://www25.senado.leg.br/web/atividade/notas-taquigraficas//notas/r/8778. Acesso em: 28 de abril de 2020.

SOLDATOS, Panayotis. An Explanatory Framework for the study of Federated States as Foreign Policy Actors. In: MICHELMANN, H; SOLDATOS. Federalism and International Relations: the role of subnational units. Oxford: Clarendon Press, 1990.

STRANGE, Susan. The retreat of the state: The diffusion of power in the world economy. Cambridge Studies in International Relations. Cambridge: Cambridge University Press, 1996.

SUPREMO TRIBUNAL FEDERAL. Ação Cível Originária 3.121/RR, Tutela Provisória, rel. min. Rosa Weber, DJ Nr. 160 do dia 08/08/2018.

SUPREMO TRIBUNAL FEDERAL. Al 400.975 AgR, rel. min. Moreira Alves, j. 25-3-2003, 1a T, DJ de 25-4-2003.

VIGEVANI, Tullo. Problemas para a atividade internacional das unidades subnacionais: Estados e municípios brasileiros. In: Revista Brasileira de Ciências Sociais, v. 21, n. 62, p. 127 - 139, 2006. 